\title{
Advances in stem cell research and therapeutic development
}

\author{
Michele De Luca ${ }^{1,9 \star}$, Alessandro Aiuti ${ }^{2,3,9}$, Giulio Cossu ${ }^{4,9}$, Malin Parmar ${ }^{5,6,9}$, Graziella Pellegrini ${ }^{7,9}$ \\ and Pamela Gehron Robey,
}

Despite many reports of putative stem-cell-based treatments in genetic and degenerative disorders or severe injuries, the number of proven stem cell therapies has remained small. In this Review, we survey advances in stem cell research and describe the cell types that are currently being used in the clinic or are close to clinical trials. Finally, we analyse the scientific rationale, experimental approaches, caveats and results underpinning the clinical use of such stem cells.

$\mathrm{O}$ ver three decades of stem cell research are currently culminating in remarkable clinical results, highlighting not only the broad applicability of these approaches, but also the immense future prospects of cell and gene therapy using adult stem cells and somatic derivatives of pluripotent stem cells (PSCs). The combined disciplines of cell and gene therapy and tissue engineering, broadly known as regenerative medicine, have the potential to revolutionize the treatment of diseases and injuries. Such advanced therapy medicinal products (ATMPs) require rigorous scientific evaluation by regulatory agencies. Marketing authorization is only granted if the product can fulfill stringent requirements for quality, safety and efficacy ${ }^{1}$.

The past decade has witnessed an exponential growth in clinical trials involving ATMPs. In a few instances, stem-cell-based therapies produced remarkable clinical results and had a striking impact on incurable diseases. However, in many cases, the scientific rationale and preclinical efficacy were unclear, and clinical trials were not efficacious-if not detrimental-for the patients ${ }^{1}$. The term 'regenerative medicine' is often loosely used to include cell-dependent, nonspecific, trophic, anti-inflammatory or immunomodulatory effects rather than bona fide regeneration of healthy tissue induced by stem cells or derivatives.

Thus, the complexity and diversity of stem-cell-based ATMPs create a need for close examination of human stem cells that are already used in clinical settings or are close to clinical trials (Fig. 1). A thorough analysis of the scientific rationale, experimental methods and results that underpin these trials will help to define general criteria that foster stem-cell-based regenerative approaches. In this Review, we focus on stem cell types and their derivatives with translational applications to date, including haematopoietic, epithelial, muscle- and tissue-specific stem cells and stem-cell-derived dopaminergic neurons. We further discuss the limitations of these treatments, ongoing challenges in the field that also include potentially harmful and unregulated procedures, and emerging opportunities.

\section{Haematopoietic stem cells}

Autologous or allogeneic HSC transplantation (HSCT) is a lifesaving procedure used after irradiation or chemotherapy. Therapyinduced cell loss is compensated by haematopoietic stem cells (HSCs), which repopulate the host bone marrow and regenerate the entire haematopoietic system. The first patients were treated in 1957 with intravenous infusions of bone marrow cells from a healthy donor following radiation and chemotherapy ${ }^{2}$. Another 20 years later, leukaemia was successfully treated ${ }^{3}$, largely through an improved understanding of graft-versus-host disease (GVHD). In 1968 , the first successful bone marrow transplantation for an inherited disorder was achieved in a 5-month-old boy with severe combined immunodeficiency (SCID) ${ }^{4}$. Over the past 50 years, HSCTs have been performed in over 400,000 individuals, becoming a curative option for haematological malignancies and severe inherited and acquired disorders of the haematopoietic system ${ }^{5}$. In addition to the regenerative potential of HSCs, allogeneic transplantations to treat neoplastic disorders also exploit graft-versus-malignancy and graft-versus-infection responses, in some cases with supplementation of cellular and/or gene therapies to complement deficient haematopoietic functions $s^{5}$. Refinements of related procedures have reduced the risks of chemotherapeutic toxicity, infection and $G$ GHD $^{5}$. Nonetheless, allogeneic HSCT still represents a challenge for future progress in clinical medicine.

Over the past 20 years, ex vivo HSC gene therapy (HSC-GT) (Fig. 2a) has emerged as an effective treatment modality for monogenic disorders, including primary immunodeficiencies, haemoglobinopathies, and metabolic disorders with neurological involvement ${ }^{6}$. Being an autologous procedure, HSC-GT does not require a compatible donor and there is no risk of GVHD or rejection, which are advantages over HSCT. The first HSC-GT medicinal product, Strimvelis, was approved in 2016 in the EU for the treatment of SCID due to adenosine deaminase (ADA) deficiency ${ }^{7}$. Based on a clinical trials.gov survey, at least five other HSC-GT products are expected to be filed for registration in the EU and USA by 2020,

\footnotetext{
'Center for Regenerative Medicine "Stefano Ferrari", Department of Life Sciences, University of Modena and Reggio Emilia, Modena, Italy. ${ }^{2}$ San Raffaele Telethon Institute for Gene Therapy (SR-Tiget) and Pediatric Immunohematology and Bone Marrow Transplantation Unit, IRCCS San Raffaele Scientific Institute, Milan, Italy. ${ }^{3}$ Vita-Salute San Raffaele University, Milan, Italy. ${ }^{4}$ Division of Cell Matrix Biology and Regenerative Medicine, Faculty of Biology, Medicine and Health, University of Manchester, Manchester, UK. ${ }^{5}$ Developmental and Regenerative Neurobiology, Department of Experimental Medical Science, Wallenberg Neuroscience Center, Lund, Sweden. ${ }^{6}$ Lund Stem Cell Center, Lund University, Lund, Sweden. ${ }^{7}$ Center for Regenerative Medicine "Stefano Ferrari", Department of Surgery, Medicine, Dentistry and Morphological Sciences, University of Modena and Reggio Emilia, Modena, Italy. ${ }^{8}$ National Institute of Dental and Craniofacial Research, National Institutes of Health, Department of Health and Human Services, Bethesda, MD, USA. ${ }^{9}$ These authors contributed equally: Michele De Luca, Alessandro Aiuti, Giulio Cossu, Malin Parmar, Graziella Pellegrini, Pamela Gehron Robey. *e-mail: michele.deluca@unimore.it
} 


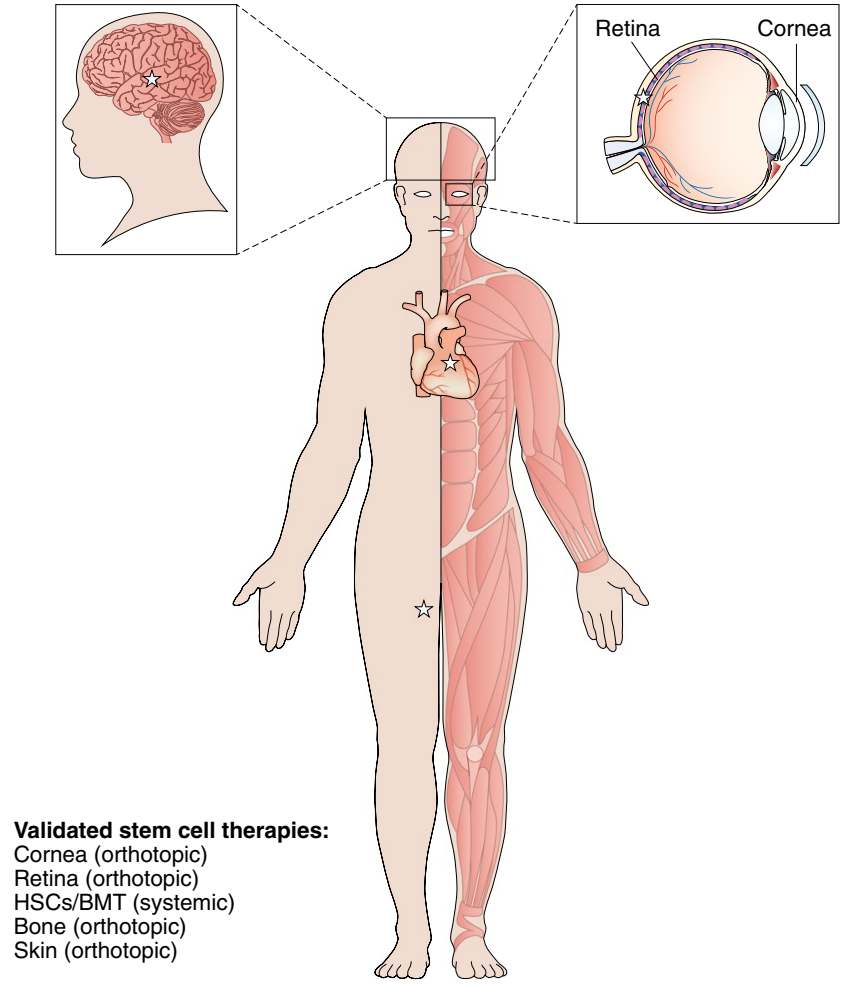

Under clinical or preclinical investigation

\section{-Immunomodulation}

-Musculoskeletal disorders (muscular dystrophies, bone diseases, joint injuries) - Cardiovascular diseases (infarct, cardiac failure, peripheral artery diseases) -Eye diseases

-Neurological disorders (Parkinson's disease, ALS, stroke, multiple sclerosis, spinal cord injury, etc.)

-Diabetes

Fig. 1 | Ongoing stem cell therapies. A simplified, non exhaustive scheme summarizing proven cell therapies (listed on the right, above) and examples of therapies still under study (listed below). Delivery of cells may be directly into the target organ (for example midbrain for Parkinson's Disease) or via the circulation (for example, HSC transplantations) or through transfer of entire cell layers to regenerate epithelia. The star denotes tissues that are under clinical or preclinical investigation for stem cell therapies.

and over 20 clinical studies are ongoing for various genetic diseases ${ }^{6}$. The success of this approach derives from the extensive clinical experience in HSCT and the ability to manipulate HSCs ex vivo and produce viral vectors that deliver the therapeutic gene to HSCs, permanently correcting HSCs and their progeny in the patient.

For the purpose of HSC-GT, autologous HSCs are collected from the patient's own bone marrow or peripheral blood after druginduced mobilization, enriched for HSCs by CD $34^{+}$cell purification and engineered with the viral vectors (Fig. $2 \mathrm{a})^{8}$. Transduced cells are then re-infused at the end of the manipulation or after a cryopreservation step. The collection, transfer, processing, sampling and shipment of human biological materials involved in autologous HSC-based GT treatment is a complex process that needs to adhere to stringent quality standards and regulations. Thus, it requires strict coordination between the sponsor and/or license holder, the good manufacturing practice (GMP) production facility and the certified transplantation centers involved in HSC collection, preparative chemotherapy and HSC-GT administration. Patients are usually administered a conditioning preparatory regimen to deplete endogenous HSCs that can be adjusted by decreasing the dosage and/or the number of chemotherapeutic and immunosuppressant agents. The use of a reduced intensity regimen was first introduced for HSC-GT to treat ADA-SCID ${ }^{10}$ and subsequently expanded to other diseases, adjusting the conditioning regimen to the therapeutic target and disease. Since 2000, 27 ADA-SCID patients in Milan have been treated with HSCs engineered with a $\gamma$-retroviral vector encoding ADA (including five patients who received infusion of Strimvelis), and all of them are alive and well ${ }^{11-13}$. In the majority of patients, HSC-GT was sufficient as a single treatment to restore immune and metabolic functions ${ }^{11,12}$.

With the exception of ADA-SCID, one severe limitation of HSC-GT based on $\gamma$-retroviral vectors was the development of haematological malignancies due to insertional mutagenesis driven by activation of cellular oncogenes from strong viral enhancers ${ }^{14,15}$. This drawback prompted the development of self-inactivating lentiviral vectors in which the expression of the therapeutic transgene is driven by a promoter, ideally of cellular origin, placed in an internal position. Preclinical studies showed that lentiviral vectors have a safer integration profile and allow for effective gene transfer into the most primitive $\mathrm{HSCs}^{8}$. Over 150 patients affected by 9 different genetic diseases have been treated with lentiviral-engineered HSCs so far ${ }^{6,12,16}$. Engineered HSCs are engrafted long-term and express the therapeutic gene, achieving evidence of clinical benefit with a favourable safety profile. The majority of HSCs can now be engineered with lentiviral vectors when measured in the infused medicinal product, leading to gene correction in $80-90 \%$ and stable engraftment in bone marrow in vivo ${ }^{17}$. In a clinical trial for $\mathrm{X}$-linked adrenoleukodystrophy, a disease characterised by demyelination and neurodegeneration, 15 out of 17 patients had stable neurological function more than two years after receiving gene therapy ${ }^{18}$. HSC-GT for early onset metachromatic leukodystrophy (MLD), a fatal lysosomal disorder involving the central and peripheral nervous system, resulted in high-level production of the therapeutic enzyme in HSCs and their progeny, in circulation and in the $\mathrm{CNS}^{19}$. Prevention of disease onset or halting of disease progression compared to that in untreated patients ${ }^{18}$ was shown in 8 out of 9 treated MLD patients. Therapeutic benefit was associated with treatment in presymptomatic patients or in those in a very early symptomatic stage.

After the genotoxic adverse events observed in the first studies of immune deficiencies, approaches to improve safety based on selfinactivating retroviral or lentiviral vectors were successfully implemented $^{20}$. In the case of Wiskott-Aldrich Syndrome (WAS), a severe disorder of immune cells and platelets, HSCs were transduced with a lentiviral vector bearing the WAS cDNA expressed under its own promoter. Interim results of three distinct clinical trials provided evidence of immunological improvement, with effective protection against infectious processes, autoimmune events and bleeding ${ }^{21-23}$.

The path to successful correction of red blood cell disorders was more challenging because of initial difficulties in achieving erythroid-specific, regulated and sustained transgene expression. Interim reports of two phase I/II clinical trials showed that HSC-GT can reduce or eliminate the need for long-term red blood cell transfusions in patients with $\beta$-thalassemia ${ }^{24,25}$. The two studies differed in the route of HSC administration (intravenous versus intrabone infusion to avoid trapping in filter organs), conditioning regimen and patients' age ${ }^{25}$. Proof of concept for successful gene transfer in sickle cell disease was shown in a patient who received HSCs transduced with a lentiviral vector encoding an anti-sickling $\beta$-globin variant $^{26}$. Further encouraging results using lentiviral-engineered HSCs have been obtained in clinical trials for ADA-SCID ${ }^{12}$, chronic granulomatous disease and Fanconi anemia ${ }^{6}$.

Genome editing approaches in HSC using site-specific endonucleases ${ }^{27}$ are also progressing to clinical application for primary immunodeficiencies and haemoglobinopathies ${ }^{6}$. These methods could be useful for disorders that require strict regulation of gene expression, such as RAG1, RAG2 or CD40-ligand immune 
a

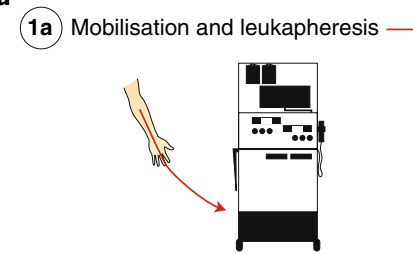

(1b)

Bone marrow harvest

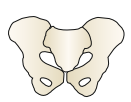

3

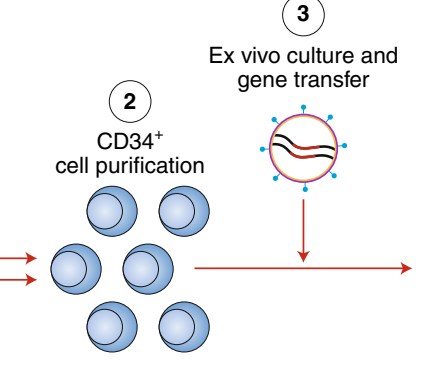

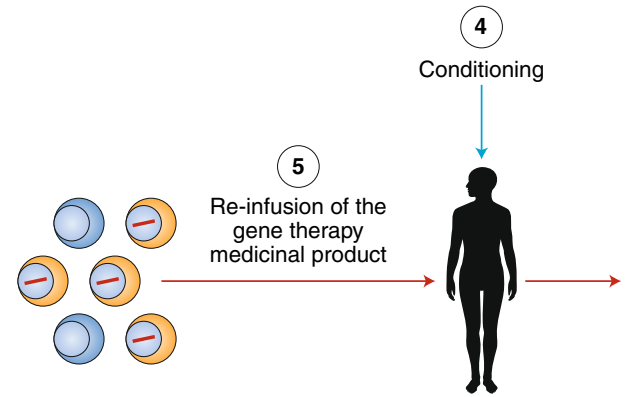

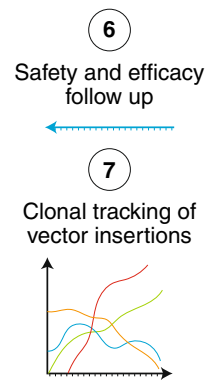

b

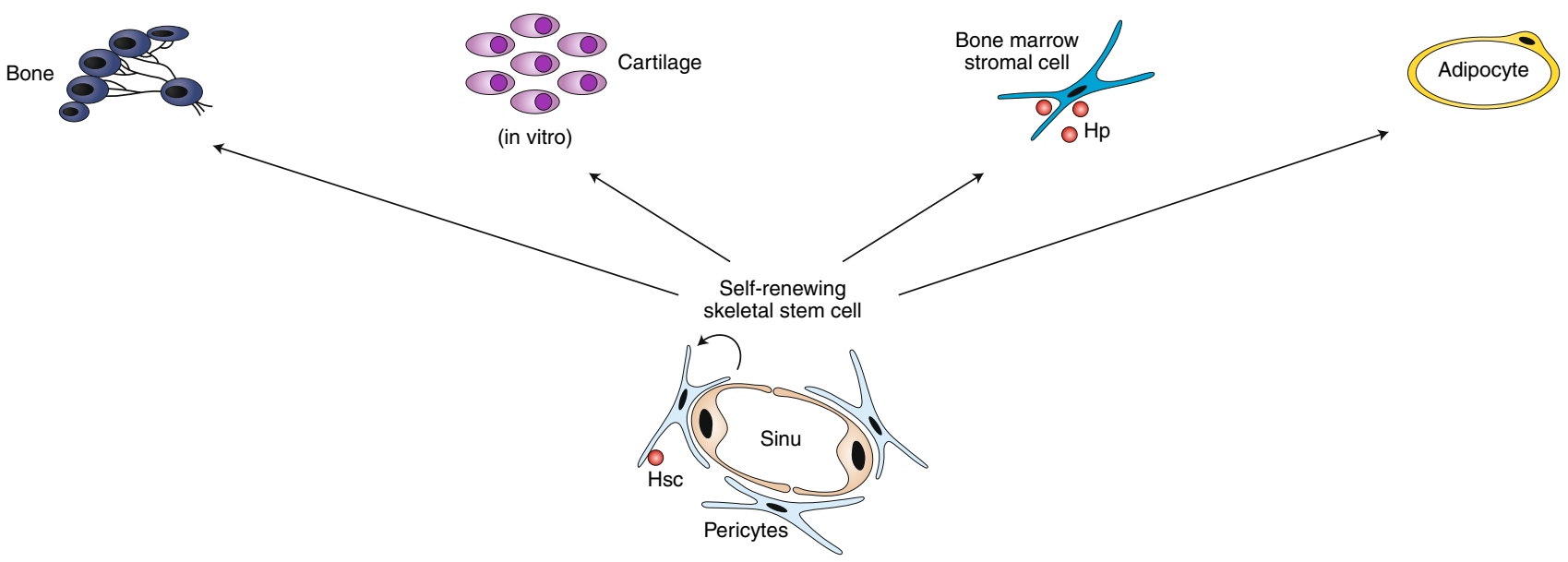

Fig. 2 | Stem cells from the bone marrow. a, Schematic representation of gene therapy with haematopoietic stem/progenitor cells (HSPC). Autologous HSPCs are collected either from the peripheral blood after drug-induced mobilization (1A) or the bone marrow. After CD34 ${ }^{+}$cell purification (2) cells are cultured ex vivo short-term and infected with a retroviral vector (gamma-retrovirus or lentiviral vector) (3). At the end of the manufacturing process, cells can be cryopreserved or prepared immediately for reinfusion. Before reinfusion of the transduced HSPCs (medicinal product), the patient receives a chemotherapy regimen with one or more drugs at a variable intensity (4). The autologous HSPCs are usually reinfused into the patient intravenously, 1-2 days after the end of chemotherapy (5). Patients are followed for several years to monitor clinical outcome (6). Insertions site analyses provide useful information on safety profiles and HSPC cell fate dynamics. b. Skeletal stem cells (SSCs) are a subset of bone marrow stromal cells (BMSCs), found as pericytes on the abluminal side of marrow sinusoids. In vivo transplantation of SSCs/BMSCs demonstrates their ability to reform pericytes (demonstration of self-renewal), and differentiate into bone, stroma that supports haematopoiesis and marrow adipocytes. When used in an in vitro pellet cell culture, they are able to form cartilage.

deficiencies. For red blood cell disorders, clinical trials involve engineered autologous HSCs to disrupt genomic loci regulating globin gene expression to increase foetal haemoglobin levels ${ }^{28}$.

Patients treated with genetically repaired HSCs represent a unique model for studying human haematopoiesis, as a substantial fraction of the engrafting HSCs and their differentiated progeny are labelled by the therapeutic vector in a unique genomic site ${ }^{19}$. Insertion-site analyses enable efficient tracking of repopulating haematopoietic cell clones across different lineages and monitoring of their behaviour during prolonged follow-ups. These analyses demonstrated sustained long-term HSC marking and multilineage potential of lentiviral-transduced HSCs and gave insights into the number of long-term HSCs that participate in haematopoietic reconstitution after HSC-GT ${ }^{19,21}$. Moreover, they showed the existence of distinct HSPC subtypes that contribute differently to early and late post-transplantation phases and identified hierarchical relationships between lineages ${ }^{29}$.

In summary, thanks to the considerable knowledge accumulated in these years and the progress in gene-editing approaches, HSC gene therapy promises to become the medicine of the future for both severe conditions with unmet medical needs and milder diseases for which allogeneic bone marrow transplantation bears excessive risks.

\section{Epithelial stem cells}

In 1975, the first human epidermal keratinocyte culture was established $^{30,31}$. Less than 10 years later, the lives of two children suffering from burns that covered more than $95 \%$ of their body surfaces were saved using grafted autologous keratinocyte cultures ${ }^{32}$. This stunning achievement heralded the age of regenerative medicine and highlighted the potential of new techniques to culture epidermal cell populations, including stem cells. To date, keratinocyte cultures have been used globally to treat an extensive number of patients with third-degree burns ${ }^{33}$.

Even though they were not called stem cells at the time, the keratinocytes cultured in 1975 matched the definition of stem cells as we know them today. In subsequent work that included clonal analysis of primary epidermal cultures, three types of clonogenic keratinocytes were identified that can generate holoclones, meroclones and paraclones $^{34}$. Keratinocytes that form holoclones possess all stem cell hallmarks and produce meroclones and paraclones with properties of transient-amplifying progenitors ${ }^{33}$. We now know that the 


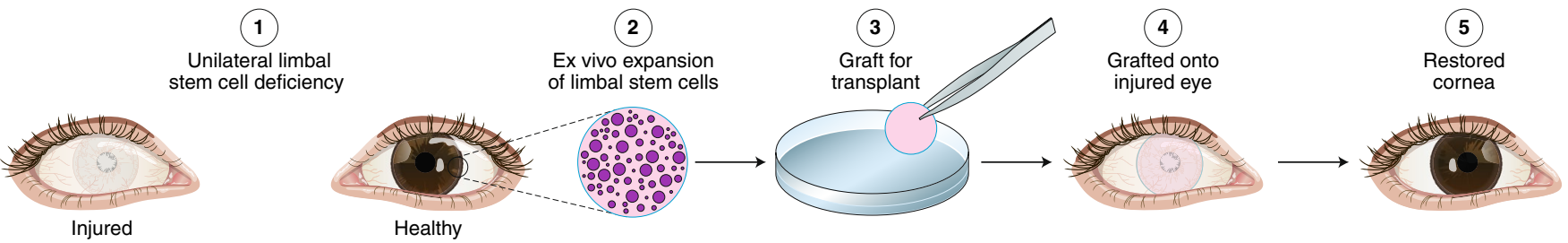

b

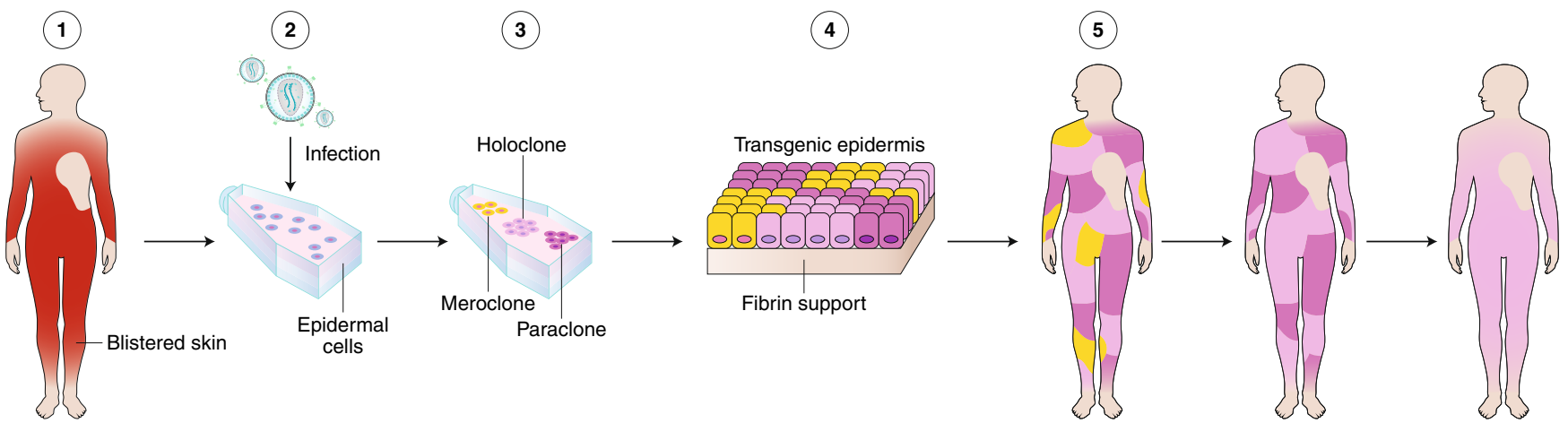

Fig. 3 | Schematic representation of corneal regeneration and combined cell and gene therapy of Epidermolysis Bullosa. a, A small (1-2 mm²) biopsy (1) is taken from the limbus of the healthy eye of patients with unilateral chemical burn-dependent total limbal stem cell deficiency (LSCD) or from a spared limbal area of patients with severe bilateral LSCD. Limbal clonogenic cells including holoclones (2) are cultivated and used to prepare autologous fibrincultured grafts (3). Grafts are then applied on the corneal surface of injured eyes (4) after removal of the the fibrovascular tissue with overlying pannus of abnormal conjunctival epithelium. Within one week after grafting, the corneal surface is covered with a transparent fully functional corneal epithelium (5). Long-term (over 20 years) follow-ups have confirmed stability and self-renewal capacity of the regenerated epithelium in hundreds of patients ${ }^{37,49}$. b, Recently ${ }^{38}$, the entire epidermis of a child who had lost $80 \%$ of his skin owing to LAMB3-dependent epidermolysis bullosa (1) has been regenerated by transgenic (2) clonogenic keratinocytes (3), able to generate cohesive sheets of transgenic, autologous cultured epidermis (4). The transgenic epidermis was formed by holoclones, meroclones and paraclones ( 3 and 4 ). Clonal tracing experiments demonstrated that the trangenic epidermis was sustained only by long-lived self-renewing stem cells (holoclones), generating pools of short-lived progenitors (meroclones and paraclones) (5). The image in $\mathbf{b}$ was adapted by permission from Springer Nature: Nature, Gene Therapy: Transgenic stem cells replace skin, Aragona, M. and Blanpain, C. (2017).

presence of holoclone-forming cells is an essential feature of epidermal grafts and is required for long-term epidermal renewal ${ }^{33,35-38}$. Failure to engraft is most likely caused by the loss of holocloneforming cells, for instance, due to inadequate culture conditions ${ }^{33}$.

Similar approaches are used for cultures of ocular limbal cells, which include stem cells of the corneal epithelium ${ }^{39-43}$. Visual acuity depends on a clear cornea, stromal avascularity and epithelial integrity. Repair and renewal of the corneal epithelium are mediated by stem cells of the limbus, the narrow zone between the cornea and the bulbar conjunctiva ${ }^{44}$. Extensive chemical burns of the cornea can damage the limbus and lead to limbal stem cell deficiency (LSCD). This condition is characterised by neovascularization, chronic inflammation, stromal scarring, corneal opacity and overall decreased visual acuity due to an invasion of bulbar conjunctival cells ${ }^{44}$. An option to prevent the conjunctival overgrowth is to restore the limbus, for instance, by grafting limbal fragments taken from the uninjured eye in unilateral LSCD ${ }^{45}$. The finding that limbal cultures ${ }^{46}$ include stem cells detectable as holoclones $^{39}$ fostered the therapeutic application of autologous limbal cultures to enable the full functional regeneration of the corneal epithelium. These procedures led to improved visual acuity in patients with unilateral LSCD and severe bilateral corneal damage $^{37,47-49}$ (Fig. 3a). An area of $1-2 \mathrm{~mm}^{2}$ of healthy limbus in an eye is enough to generate limbal cultures that allow the restoration of the corneal epithelium of both eyes ${ }^{37,49}$. Colony size, epithelial cell growth rates and number of limbal clonogenic cells are not able to predict clinical outcomes ${ }^{49}$, indicating that the bulk of clonogenic keratinocytes likely behave as transient progenitors. Evidence also suggests that transient progenitors adjacent to epidermal stem cells promote adequate stem cell function, particularly during tissue regeneration ${ }^{50}$.

The discovery of the transcription factor p63 as an important regulator in squamous epithelia further helped in the establishment of criteria to measure stem cell content in limbal cultures ${ }^{51-54}$. In particular, the $\Delta \mathrm{Np} 63 \alpha$ isoform indicates the proliferative capacity of epithelial stem cells ${ }^{54}$. Expression decreases during clonal transition from holoclone to meroclone and is lacking in paraclones ${ }^{55,56}$. Measurements of $\Delta \mathrm{Np} 63 \alpha$ abundance in holoclones can be used to estimate the number of stem cells in a limbal culture ${ }^{57}$. Strikingly, successful application of limbal cultures in the clinic correlated with a defined percentage of $\mathrm{p} 63^{\text {bright }}$ holoclones ${ }^{37,49}$. As of yet, no correlation with clinical success or long-term (20 years of follow-up) corneal stability has been found for other suggested limbal stem cell markers ${ }^{33,58,59}$. Although the regeneration of the avascular corneal epithelium alleviates symptoms (burning, pain, and photophobia), full recovery of visual acuity in patients with stromal scarring requires a keratoplasty, which would not be successful in the absence of a functional, fully restored corneal epithelium ${ }^{37}$.

In 2015, autologous limbal cultures were the first stem-cellbased ATMP to receive marketing authorization from the European Medicine Agency (Holoclar). Many other groups worldwide have used limbal cultures to treat ocular burns, often with different culture systems $s^{33,58,59}$. Measurement of the correlation between epithelial clonal types and clinical outcomes was not performed in any of those studies. Epithelial regeneration in skin and ocular burns using keratinocyte cultures provided only indirect, though compelling, evidence for the identification of holoclone-forming cells as longlived stem cells sustaining human squamous epithelia. The formal 
proof came from combined ex vivo cell and gene therapy 30 years after the first clinical application of epidermal cultures ${ }^{38}$.

Epidermolysis bullosa is a rare inherited disorder of the integuments. Four main types of the disease exist, which differ in severity and prevalence: epidermolysis bullosa simplex (EBS), junctional epidermolysis bullosa (JEB), dystrophic epidermolysis bullosa (DEB), and Kindler syndrome ${ }^{60}$. JEB originates from mutations in three genes ( $L A M A 3, L A M B 3$ or $L A M C 2$ ) that jointly encode laminin 332 (also referred to as laminin 5) and in genes that encode collagen XVII or for $\alpha 6 \beta 4$ integrins ${ }^{60}$. The complete absence of laminin 332 is typically lethal early in life ${ }^{60}$. In non-lethal generalized JEB, laminin 332 is substantially decreased and hemidesmosomes are underdeveloped or absent. These deficiencies result in blisters and erosions of the skin and mucosa within the lamina lucida of the basement membrane in response to minor trauma. Extensive chronic skin wounds are detrimental to the patients' quality of life and result in recurring infections and scars. Furthermore, individuals with generalized recessive DEB and JEB are prone to developing aggressive squamous cell carcinomas as the disease progresses. No cure exists for JEB to date ${ }^{60,61}$.

Autologous, stem-cell-containing epidermal cultures were first transplanted to treat $L A M B 3$-deficient JEB. Cells were genetically modified using a $\gamma$-retroviral vector $(\gamma \mathrm{RV})$ expressing full-length $L A M B 3$ cDNA under the control of the Moloney leukaemia virus long-terminal repeat ${ }^{62,63}$. Recently, such combined ex vivo cell and gene therapy has proved to be life-saving, as it achieved regeneration of the entire epidermis of the patient, a seven-year-old child suffering from a devastating form of JEB with poor prognosis ${ }^{38}$ (Fig. 3b). At the last follow-up, the patient's transgenic epidermis expressed normal levels of laminin 332 and had normal thickness and morphology of hemidesmosomes and an intact basement membrane ${ }^{38}$.

Of note, the absence of clonal selection in the transgenic epidermis was confirmed both in vitro and in vivo ${ }^{38}$. The three patients with JEB that were treated with $\gamma$ RV-transduced epidermal cultures received $\sim 4 \times 10^{8}$ transgenic clonogenic keratinocytes and did not manifest tumour development or other adverse events (3.5-13 years follow-up $)^{38,62,63}$. A similar $\gamma \mathrm{RV}$ vector was in use for phase I and II clinical trials on recessive $\mathrm{DEB}^{64}$. Nevertheless, as with HSCs, the development of safer viral vectors is desirable for epidermal cultures.

Similarly to HSCs, clonal tracing experiments, using retroviral integrations as clonal genetic marks, answered the question as to whether the mammalian epidermis is sustained by a population of equipotent progenitors that directly, and perhaps stochastically, generate differentiated cells during the lifetime of the animal ${ }^{65}$ or by long-lived stem cells that establish pools of short-lived progenitors ${ }^{66}$. The patient's transgenic epidermis unambiguously proved three premises. First, holoclone-forming cells, but not meroclones and paraclones, are able to extensively self-renew, both in vitro and in vivo. Second, meroclones and paraclones are transient progenitors that are progressively lost within a few months after transplantation. Third, the human epidermis is sustained by a limited number of long-lived stem cells (holoclones) that generate short-lived progenitors. These progenitors continue for some time, replenish differentiated cells and can contribute to wound healing for a short duration $^{38}$ (Fig. 3b). It would be of great interest to establish whether all holoclone-forming cells are identical or if a hierarchy exists amongst them.

For this reason, the most important attribute of a cultured epithelial graft is the presence and maintenance of an adequate number of stem cells detected as holoclones. This criterion is of paramount importance to ensure graft quality and increase the likelihood of a successful treatment. Hence, it should be carefully evaluated before a newly developed keratinocyte culture system is transitioned into a clinical setting. The knowledge and experience acquired in decades of research on epithelial stem cells and their clinical application is currently driving several clinical trials tackling different forms of epidermolysis bullosa.

\section{Striated muscle stem/progenitor cells}

Despite a number of structural and functional similarities, skeletal and cardiac muscle differ in their embryological origins $s^{67,68}$ and regeneration potency ${ }^{69}$. In mammals, skeletal muscle robustly regenerates after acute and chronic injury ${ }^{70}$, whereas cardiac muscle does not (or does so to a negligible extent) ${ }^{71,72}$, beyond the first days of post-natal life ${ }^{73}$. From this observation it may be that skeletal muscle contains stem cells, but cardiac muscle does not. Although this is likely the case, we still know little, especially about the heart, and any clinical use of so-called 'stem cells' in diseases of skeletal and cardiac muscle has resulted in a negative outcome ${ }^{74}$.

In the case of skeletal muscle, the bona fide stem cell is the satellite cell, first described by Mauro in $1961^{75}$. Satellite cells can be defined by their position between the muscle membrane and the basal lamina and by expression of the paired-ruled gene Pax7. Conversely, the paralogue Pax3 is predominantly expressed in satellite cells of the foetus and certain adult muscles ${ }^{76}$. Satellite cells contribute to postnatal muscle growth and, with sexual maturity, enter quiescence. Upon injury they are reactivated and contribute myogenic cells to muscle-fiber repair or replacement, as well as new stem/progenitor cells ${ }^{77}$. Satellite cells are currently the subject of intense investigation, focused mostly on their role in regeneration and senescence. Satellite cell origin and their role in postnatal growth are much less studied. Even though serial transplantation experiments established their stemness in mouse cells ${ }^{78}$, human cells have limited selfrenewal ability, as demonstrated by their exhaustion in more severe forms of muscular dystrophies with repeated degeneration-regeneration cycles $^{79}$. In the 1990s, following successful transplantation of satellite cells into mouse muscle ${ }^{80}$, several clinical trials were carried out for cell transplantations in Duchenne muscular dystrophy $(\mathrm{DMD})^{81}$. After in vitro expansion, satellite-cell-derived progenitors were directly injected into a small number of patient muscles, with no toxicity or efficacy even though donor nuclei and donor dystrophin were detected in the individuals ${ }^{82}$. Failure to engraft due to the death of transplanted cells and little migration from the injection site makes intramuscular transplantation of large muscles extremely challenging, if at all possible ${ }^{83}$. More recently, intramuscular injection into the pharyngeal muscles brought about some clinical benefit in people affected by oculopharyngeal muscular dystrophy, which causes progressive difficulty in swallowing ${ }^{84}$. Other clinical trials using satellite-cell-derived progenitors are ongoing for local damage to muscle, such as sphincter incontinence ${ }^{85,86}$. Trials report some clinical benefit ${ }^{87}$, but outcome measures and study designs are not easy given the heterogeneity of patient populations and the varying severity of these lesions. In addition to satellite cells, skeletal muscle contains many other cell types, some initially identified by classic histology (fibroblasts, vessel pericytes, smooth muscle, endothelium, Schwann cells and tenocytes) and some more recently identified by the expression of specific markers such as $\mathrm{Pw} 1\left(\mathrm{PW}^{+}\right)$ $\mathrm{Pax}^{-}$interstitial cells (PICs) ${ }^{88}$ ) or PDGFR $\alpha$ (fibro-adipogenic progenitors ${ }^{89}$ ). None of these cells have been characterised as stem cells, and they likely are not, but some may participate in muscle growth or regeneration. Mesoangioblasts are in vitro counterparts of muscle perivascular cells ${ }^{90}$ that express tissue non-specific alkaline phosphatase (TNAP). Through the use of a TNAP-Cre mouse, mesangioblasts were shown to contribute to a limited extent to muscle growth and regeneration ${ }^{91}$. Human mesoangioblasts were intra-arterially transplanted into patients with DMD (because of their ability to cross inflamed vessel walls) in a trial that confirmed their safe use but lacked clinical efficacy, probably owing to very low engraftment levels ${ }^{92}$. Low survival, consequently poor engraftment and low migration are all issues that need to be resolved before clear clinical efficacy can be reached. Nevertheless, poorly controlled 
clinical trials continue, often on a commercial basis, and cause emotional and economical damage to DMD families.

In the case of cardiac stem cells, about 20 years of work, both in preclinical models and clinical trials, with different cell types and cardiac pathologies (though mainly myocardial infarction) generated a huge number of reports (for a meta-analysis, see ref. ${ }^{93}$ ). Recently, a commentary presented a critical view on the experimental work that had served as a basis for many clinical trials ${ }^{74}$. Cardiac diseases typically have a much higher incidence than skeletal muscle diseases. In 2001, a controversial paper showed efficient cardiac regeneration following transplantation of bone marrow cells after myocardial infarction ${ }^{94}$. Other laboratories were unable to reproduce these data, with a growing consensus that the beneficial effect of cell transplantation, at best modest and transient, is likely due to secretion of paracrine factors that may promote cardiomyocyte survival and/or angiogenesis ${ }^{95}$. The same explanation seems to apply for most cell types transplanted into the infarcted heart, including different progenitor cells isolated from the heart itself on the basis of markers such as cKit, Islet-1 and Sca-1, to name a few examples $^{96,97}$. Another elegant and rigorous study, in which cardiac and non-cardiac cells were double labelled, demonstrated that cardiac cells readily generate non-cardiac cells during development, but this does not occur in the adult, even after injury ${ }^{98}$. Cardiac progenitors, derived from reprogrammed or embryonic stem cells (ESC), have been tested only in animal models to date; however, their differentiation into cardiac cell types seems more controlled ${ }^{99,100}$, and their contribution to the regenerating myocardium is far more significant ${ }^{101}$. Extensive rebuilding of the myocardium has been achieved using human ESC-derived cardiomyocytes in primate hearts ${ }^{102}$, though applying this strategy in patients would still require substantial in vitro cell expansion and life-long immune suppression. In addition, newly generated cardiomyocytes are embryonic in size (one third of the adult size), and this limitation may easily cause arrhythmias $^{103}$. A different route, tested only preclinically to date, is to avoid cell transplantation ${ }^{104}$ and promote regeneration using different strategies. One option would be to activate endogenous cardiac progenitors in situ (if they exist) or trans-differentiate resident fibroblasts into cardiomyocytes through delivery of cardiac master genes $^{105}$. Other strategies might include the application of external cardiac patches ${ }^{106}$ or the induction of partial reprogramming in $\operatorname{situ}^{107,108}$, assuming that incomplete reprogramming does not erase cell identity, which would lead to an expansion of immature cells that could differentiate into cardiomyocytes and vascular cells.

In conclusion, despite much experimental and clinical work, we still know relatively little about striated muscle stem/progenitor cells, and future clinical trials will certainly benefit from a deeper understanding of these cells and their regenerative potency.

\section{Tissue-specific stem/progenitor cells}

The term "mesenchymal stem (stromal) cell" is broadly used and has come to mean any adherent fibroblastic population of cells, even those that are not stem cells based on rigorous criteria ${ }^{109,110}$. The term was based on the pioneering work by Friedenstein and Owen (reviewed in ref. ${ }^{111}$ ), who first described a population of clonogenic, non-hematopoietic bone marrow stromal cells (BMSCs) that were able to recreate cartilage, bone, haematopoiesis-supporting stroma and marrow adipocytes (now termed skeletal stem cells, $\mathrm{SSCs}^{112}$ ) on the basis of in vivo transplantation studies. Due to their multipotency, it was speculated that these cells could form other mesodermal connective tissues outside their lineage (muscle, tendon, ligament, adipose tissue and others). For this reason, they were renamed "mesenchymal stem cells" ${ }^{113}$. However, this term is biologically incorrect for two reasons. The mesenchyme is an embryonic connective tissue that gives rise to connective tissues, blood and blood vessels. No postnatal stem cell has this ability (https:// embryo.asu.edu/pages/mesenchyme). Second, different connective tissues derive from different specifications of neural crest and mesoderm cells ${ }^{114}$ (Fig. 2b). No common "mesenchymal stem cell" exists during development or in the postnatal organism.

Despite the ambiguous identity of "mesenchymal stem cells" from different tissues and an inadequate understanding of their functions in most cases, ongoing efforts are made to use these cells in a clinical setting ${ }^{115}$. A serious development in recent years was the highly questionable use of uncharacterised cells in unregulated procedures that sometimes had harmful consequences for patients ${ }^{116}$. In regenerative medicine, "mesenchymal stem cells," now renamed "medicinal signalling cells," 117 are being used to treat a long list of diseases and disorders based on their putative paracrine, immunomodulatory and immunosuppressive effects. So far, over 900 clinical trials are officially registered, many without a reasonable basis (https:// clinicaltrials.gov/). Studies indicate that upon systemic infusion or direct injection, these cells rapidly disappear ${ }^{118}$. The rationale for their use and mechanism of action are equally unclear ${ }^{119}$. Labelling these treatments as 'stem cell' therapies is highly misleading without evidence that paracrine or immunomodulatory effects originate from a stem cell subset. Any putative effect is based on the effects of the entire population of cells, most of which are not stem cells. Even though some clinical studies using "mesenchymal stem cells" or "medicinal signaling cells" are indicated as safe, results for the majority of trials listed are unavailable. Based on a handful of published studies, outcomes have often failed to meet expectations. For example, a recent study utilizing 'cardiopoietic' cells derived from "mesenchymal stem cells" failed to show improvement of advanced ischaemic heart failure ${ }^{120}$. Likewise, a study using fat-derived "mesenchymal stem cells" failed to demonstrate closure and healing of perianal fistulas ${ }^{121}$, although some suggest that more encouraging results were reported from a better designed clinical trial ${ }^{115}$. However, the magnitude of the improvement, its persistence and potential mechanisms are not well known at this time.

In addition to clinical trials, large numbers of people pay for unregistered treatments in private clinics around the world without approval from regulatory bodies ${ }^{122}$. Many are using raw concentrates of whole bone marrow and liposuction aspirates. Detrimental adverse effects such as acute vision loss have been reported in patients treated for macular degeneration by bilateral, direct injection of liposuction aspirates ${ }^{116}$. These unfortunate cases highlight the urgent need to better educate the public, practicing physicians and also biomedical researchers about what "mesenchymal stem cells" are and how they can be used therapeutically in an appropriate and effective fashion. Importantly, clear guidance should be created on materials unsuitable for clinical use ${ }^{122}$.

However, it is essential to note that bona fide tissue-specific stem/progenitor cells (TS/PCs) do exist in some tissues reported to contain "mesenchymal stem cells". We advocate that in any attempt to classify and define these populations, cells should be named after their tissue of origin and their differentiation capacity, as established by rigorous assays. In bone, skeletal stem cells are identified on the basis of their ability to generate cartilage, bone, stroma and marrow adipocytes ${ }^{12,114}$ (Fig. 2b). In adipose tissue, TS/PCs should be called adipose stem/progenitor cells based on their ability to form adipocytes. Many tissues contain fibroblasts that have similar cell surface markers, but these markers are not specific and cannot be used to qualify any population of cells as stem cells as has been suggested ${ }^{109,123}$.

In various human tissues, CD146 ${ }^{+}$cells (negative for CD45 and CD31) are clonogenic, a feature common to many types of stem cells $^{124,125}$. Although cell-surface markers were nearly identical, transcriptome analyses and differentiation assays revealed marked differences in their CD146 ${ }^{+}$cell inherent differentiation capacities ${ }^{124}$. In addition, CD146 ${ }^{+}$cells were, in fact, identified as pericytes, cells that wrap around nascent blood vessels and stabilize them ${ }^{124,126}$. The pericytic nature of skeletal stem cells in bone marrow is supported 
by fate mapping of Lepr ${ }^{+}$cells in mice ${ }^{127}$. This intriguing finding supports the notion that the formation of pericytes in different tissues is a common developmental process, whereby in-growing blood vessels capture local cells at different stages of lineage commitment ${ }^{110}$. These cells remain quiescent on the blood vessel surface until activated by injury or during tissue remodelling and replenish the tissue of origin, but cannot transdifferentiate into functional cell types outside their lineage ${ }^{110}$. By contrast, a study that used Tbx18 as a pericytic marker did not identify pericytes in other tissues as resident progenitor cells ${ }^{128}$. Clearly, additional work is needed to test this hypothesis.

Albeit rare, some positive clinical examples for the application of TS/PCs to regenerate functional tissues exist. Quarto, Cancedda and coworkers have treated three people who have large bone defects with ex vivo expanded autologous SSCs/BMSCs with good results $^{129}$, and a number of small studies followed ${ }^{130,131}$. However, tissue engineering with SSCs/BMSCs has not become a mainstay in orthopaedics for a number of reasons, which include lengthy ex vivo expansion of autologous cells, the lack of weight-bearing scaffolds that support SSC and BMSC growth and differentiation and overall slow vascularization ${ }^{132}$. Likewise, stem cells within expanded autologous populations of the dental pulp were transplanted into pulpectomized teeth and could regenerate pulp and dentin based on radiographic evidence ${ }^{133}$. In these two studies, and contrary to the reports on ADA-SCID or epidermolysis bullosa ${ }^{29,38}$, it was not possible to determine whether the regenerated tissue emanated from the exogenous cells because of a lack of markers. Nonetheless, these studies highlight that the functional capabilities of TS/PCs can be harnessed for therapy. Future studies will be essential to fully delineate these specific properties, which will undoubtedly lead to major advances in therapies based on appropriately characterised and verified stem cells.

\section{PSC-derived cells in regenerative neuroscience}

Cell replacement via transplantation of foetal cells has been developed as a therapeutic strategy to replace lost neurons in acute and progressive neurodegenerative disorders such as Parkinson's and Huntington's diseases, retinal degenerative disorders and stroke ${ }^{134-140}$. Although some of these studies have shown promising results, especially in Parkinson's Disease, they also highlight the difficulty of using foetal tissue as a cell source, and the necessity to develop readily available, bankable and quality-controlled cells for clinical use. Advances in PSC differentiation protocols have made the clinical use of PSC-derived cells feasible at a larger scale. Clinical trials have now been launched to treat spinal cord injury ${ }^{141}$. In ophthalmology, PSC-derived retinal pigment epithelial cells have been transplanted into patients with age-related macular degeneration ${ }^{142,143}$ (Fig. 4). Both trials have confirmed the safety and feasibility of the method ${ }^{142,143}$, and functional efficacy has been demonstrated in patients grafted with human ESC-derived retinal epithelial cells on a synthetic basement membrane ${ }^{142}$. These pioneering trials have served as a great encouragement and inspiration by providing important proof-of-concept data. They also guided the discussion of preclinical safety and tumourigenicity studies and thus paved the way for regulatory approval of other PSC-derived products in regenerative neuroscience targeted to neurodegenerative diseases. Here, we will focus on developments in the field of Parkinson's Disease, in which most foetal cell transplantation trials have been performed ${ }^{135}$, with stem cells now entering clinical trials ${ }^{136}$.

Parkinson's disease is the second most common neurodegenerative disorder, characterised by a progressive loss of midbrain dopaminergic neurons, which results in reduced dopamine levels in the striatum that underlie the motor dysfunctions of the disease $^{144}$. The most common treatment for Parkinson's disease today is increasing dopamine levels in the brain using dopaminergic drugs. Patients typically respond well to this treatment in the early stages of the disease, but prolonged medication, delivered in a nonphysiological and non-localized manner, is associated with adverse effects, such as dyskinesia and neuropsychiatric complications ${ }^{145,146}$. Conceptually, cell-based therapy aims to replace lost dopamineric neurons with new healthy cells tasked to increase dopamine levels in a regulated fashion locally in the Parkinsonian striatum (putamen and caudate). The idea was first tested over 30 years ago by transplanting foetal ventral midbrain tissue into the putamen of patients with Parkinson's disease ${ }^{147,148}$ (Fig. 4). Since then, a few hundred patients in Europe, the US and Canada have received foetal ventral midbrain transplants ${ }^{135}$. These trials have provided important evidence that restoration of dopaminergic striatal innervation can indeed provide long-term clinical benefits in patients with Parkinson's disease ${ }^{135}$. Outcomes of these trials, however, have been highly variable, and their fidelity has been questioned ${ }^{135}$. With time, it has become clear that some grafted patients have a substantial and long-term effect from their transplants ${ }^{149}$. These findings are in agreement with functional PET imaging demonstrating restored dopaminergic transmission, and postmortem analyses of brains decades after transplantation indicate long-term graft survival and extensive innervation of host putamen ${ }^{150-153}$. At the same time, other patients showed no, or only modest, clinical improvements and side effects in the form of graft-induced dyskinesia have been observed in a significant number of patients ${ }^{135}$. Moreover, postmortem analysis revealed Lewy body pathology in the transplanted cells ${ }^{153,154}$.

Even so, preclinical and clinical work spanning over 30 years corroborate that regenerative transplantation therapy in Parkinson's disease is achievable. However, cell-based therapy using foetal cells is not a viable option for the future due to scarcity of donor tissue. An expandable source of cells that can be supplied on demand and in sufficient quantities is needed to circumvent the problems currently associated with foetal tissue grafting. The use of such cells will also provide better possibilities for standardization and quality control, which are needed for a more robust outcome in patients. The most obvious choice might be to expand cells from foetal ventral midbrain tissue prior to transplantation. However, it has proven difficult to sufficiently expand neural progenitors while maintaining their capacity to differentiate into authentic and functional dopaminergic neurons ${ }^{155}$. With the first report of human ESC cultures in $1998^{156}$, and human induced PSCs in $2007^{157}$, new possibilities for obtaining an unlimited source of dopaminergic neurons have become available. A number of early studies succeeded in generating neurons, including dopaminergic-like neurons from human $\mathrm{ESCs}^{135}$. In the early 2010s, protocols that mimicked the developmental trajectory of midbrain dopaminergic neurons reported the generation of authentic dopaminergic neurons of midbrain identity that survived, integrated and functionally matured in preclinical models of Parkinson's disease ${ }^{158,159}$. Importantly, the stem-cell-derived dopaminergic neurons and their progenitors are molecularly and functionally similar to the cells from foetal ventral midbrain tissue ${ }^{159-161}$, providing evidence that these cells are of a quality needed for use in patients. These results enabled GMP adaptation and the development of cell manufacturing regimes for generating cryopreserved dopaminergic progenitors for use in clinical trials (Fig. 4). These first-in-human, PSC-based trials were designed on the basis of important aspects learned from the foetal cell trials, conducted in 1980-1990, as well as the currently ongoing EU-funded multicenter foetal ventral midbrain transplantation trial TRANSEURO ${ }^{135}$. The knowledge gained has helped researchers decide on cell dosing, surgical parameters, patient selection, immune suppression and appropriate outcome measures in current trials, thereby increasing the chances of success.

It should be noted that a new level of complexity arises, related to the fact that stem-cell-derived products (unlike foetal cells) are regulated as ATMPs. Nevertheless, a number of centers around the 


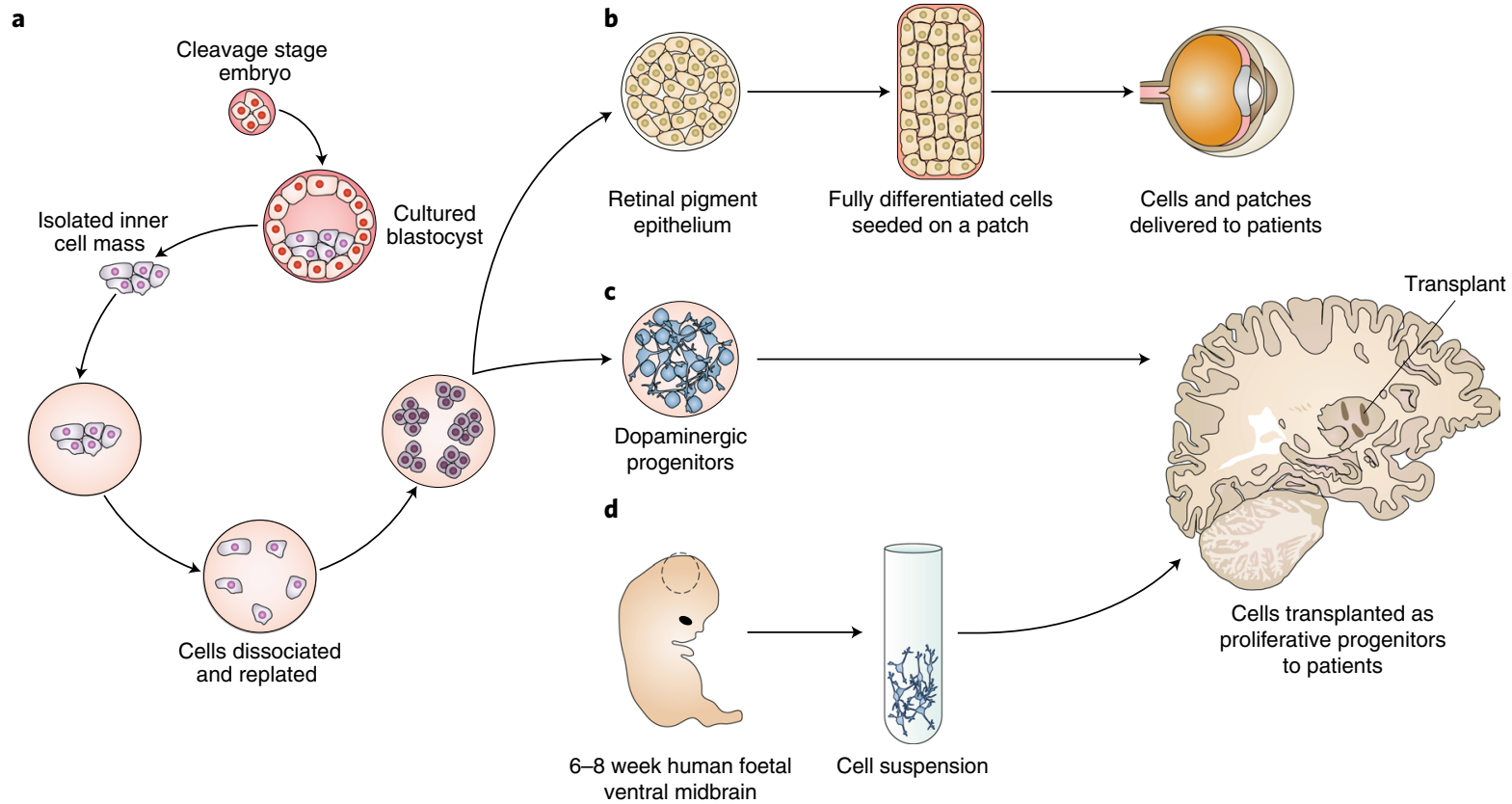

Fig. 4 | Ongoing therapies using ESC-derivatives. a, Human embryonic stem cells (hESCs) are derived from supernumerary pre-implantation embryos and can be grown in culture indefinitely. These cells are pluripotent and can give rise to any cell type in the body. b, Fully mature retinal pigment epithelium (RPE) cells derived from hESCs and seeded on a patch have been transplanted into eyes of patients with age-related macular degeneration (AMD). c, For cell-based therapy in Parkinson's Disease, ESC-derived neural progenitors with the capacity to give rise to fully mature and functional neurons are transplanted into the brain. d, Proof of concept that transplantation of dopaminergic progenitors can work comes from clinical trials in which these cells have been harvested from human foetal brain and transplanted into the putamen of patients with Parkinson's Disease.

world are now at the verge of entering clinical trials ${ }^{162-164}$. In this capacity, different groups have come together to jointly tackle issues related to preclinical assessments, manufacturing, safety and efficacy testing, and fast-track therapies on route to the clinic within a network called GForce-PD ${ }^{136,165}$. These are exciting times in Parkinson's disease research and likely also spur the development of new regenerative approaches in other neurodegenerative diseases.

\section{Conclusion}

Almost 30 years of intense basic and clinical research were necessary to translate knowledge gained on haematopoietic and epithelial stem cells into defined and reproducible therapies that can cure or alleviate diseases. During the same timeframe, cell-based treatments for Parkinson's and retinal diseases have undergone a similar development. These achievements required in-depth knowledge of the biology of specific stem cells and their derivatives, of lineage relationships, cellular functions and signalling mechanisms in homeostasis and disease. However, their success also relied greatly on adequate and feasible clinical protocols. In the case of blood and squamous epithelia, protocols were relatively easy to develop: HSCs are delivered by intravenous infusion, whereas squamous epithelial cultures and retinal pigment epithelial cells require transplantation onto a properly prepared body surface. Somewhat more complex, CNS cell replacement requires neurosurgery and delivery methods that have been developed in parallel to cell generation. Translation of stem cell biology into clinical practice to treat complex, vascularized tissues or organs is intuitively much more multifaceted as well, owing to the difficulty in ablating the resident diseased cells, thus creating space for donor cell engraftment. Removal of diseased haematopoietic or skin stem cells is easily attained, but it would be cumbersome, for instance, in the skeleton or the muscle. The analysis of success or failure of stem-cell-based therapies will contribute to a deeper understanding of the biology of specific stem cells, as exemplified by trials with haematopoietic and epidermal stem cells.
The criteria developed in successful clinical applications of defined stem cells will provide blueprints that can be applied to other stemcell-based cell and gene therapies that are currently in development.

Received: 6 August 2018; Accepted: 9 May 2019;

Published online: 17 June 2019

\section{References}

1. Sipp, D. et al. Marketing of unproven stem cell-based interventions: a call to action. Sci. Transl. Med. 9, eaag0426 (2017).

2. Thomas, E. D., Lochte, H. L. Jr., Lu, W. C. \& Ferrebee, J. W. Intravenous infusion of bone marrow in patients receiving radiation and chemotherapy. N. Engl. J. Med. 257, 491-496 (1957).

3. Thomas, E. D. et al. One hundred patients with acute leukemia treated by chemotherapy, total body irradiation, and allogeneic marrow transplantation. Blood 49, 511-533 (1977).

4. Gatti, R. A., Meuwissen, H. J., Allen, H. D., Hong, R. \& Good, R. A. Immunological reconstitution of sex-linked lymphopenic immunological deficiency. Lancet 2, 1366-1369 (1968).

5. Chabannon, C. et al. Hematopoietic stem cell transplantation in its 60s: a platform for cellular therapies. Sci. Transl. Med. 10, eaap9630 (2018).

6. Dunbar, C. E. et al. Gene therapy comes of age. Science 359, eaan4672 (2018)

7. Aiuti, A. et al. Gene therapy for immunodeficiency due to adenosine deaminase deficiency. N. Engl. J. Med. 360, 447-458 (2009).

8. Naldini, L. Gene therapy returns to centre stage. Nature 526, 351-360 (2015).

9. Bernardo, M. E. \& Aiuti, A. The role of conditioning in hematopoietic stem-cell gene therapy. Hum. Gene Ther. 27, 741-748 (2016).

10. Aiuti, A. et al. Correction of ADA-SCID by stem cell gene therapy combined with nonmyeloablative conditioning. Science 296, 2410-2413 (2002).

11. Cicalese, M. P. et al. Update on the safety and efficacy of retroviral gene therapy for immunodeficiency due to adenosine deaminase deficiency. Blood 128, 45-54 (2016).

12. Kohn, D. B. et al. Consensus approach for the management of severe combined immune deficiency caused by adenosine deaminase deficiency. J. Allergy Clin. Immunol. 143, 852-863 (2018).

13. Tucci, F. et al. Successful treatment with ledipasvir/sofosbuvir in an infant with severe combined immunodeficiency caused by adenosine deaminase 
deficiency with HCV allowed gene therapy with strimvelis. Hepatology 68, 2434-2437 (2018).

14. Hacein-Bey-Abina, S. et al. A serious adverse event after successful gene therapy for X-linked severe combined immunodeficiency. N. Engl. J. Med. 348, 255-256 (2003).

15. Braun, C. J. et al. Gene therapy for Wiskott-Aldrich syndrome-long-term efficacy and genotoxicity. Sci. Transl. Med. 6, 227 ra33 (2014).

16. Cavazzana, M., Bushman, F.D., Miccio, A., André-Schmutz, I. \& Six, E. Gene therapy targeting haematopoietic stem cells for inherited diseases: progress and challenges. Nat. Rev. Drug Discov. https://doi.org/10.1038/ s41573-019-0020-9 (2019).

17. Cartier, N. et al. Hematopoietic stem cell gene therapy with a lentiviral vector in X-linked adrenoleukodystrophy. Science 326, 818-823 (2009).

18. Sessa, M. et al. Lentiviral haemopoietic stem-cell gene therapy in early-onset metachromatic leukodystrophy: an ad-hoc analysis of a non-randomised, open-label, phase 1/2 trial. Lancet 388, 476-487 (2016).

19. Biffi, A. et al. Lentiviral hematopoietic stem cell gene therapy benefits metachromatic leukodystrophy. Science 341, 1233158 (2013).

20. De Ravin, S. S. et al. Lentiviral hematopoietic stem cell gene therapy for X-linked severe combined immunodeficiency. Sci. Transl. Med. 8, 335ra57 (2016)

21. Aiuti, A. et al. Lentiviral hematopoietic stem cell gene therapy in patients with Wiskott-Aldrich syndrome. Science 341, 1233151 (2013).

22. Ferrua, F. et al. Lentiviral haemopoietic stem/progenitor cell gene therapy for treatment of Wiskott-Aldrich syndrome: interim results of a nonrandomised, open-label, phase 1/2 clinical study. Lancet Haematol. 6, e239-e253 (2019).

23. Hacein-Bey Abina, S. et al. Outcomes following gene therapy in patients with severe Wiskott-Aldrich syndrome. J. Am. Med. Assoc. 313, 1550-1563 (2015).

24. Thompson, A. A. et al. Gene therapy in patients with transfusiondependent $\beta$-thalassemia. N. Engl. J. Med. 378, 1479-1493 (2018).

25. Marktel, S. et al. Intrabone hematopoietic stem cell gene therapy for adult and pediatric patients affected by transfusion-dependent $B$-thalassemia. Nat. Med. 25, 234-241 (2019).

26. Scala, S. et al. Dynamics of genetically engineered hematopoietic stem and progenitor cells after autologous transplantation in humans. Nat. Med. 24, 1683-1690 (2018).

27. Vakulskas, C. A. et al. A high-fidelity Cas9 mutant delivered as a ribonucleoprotein complex enables efficient gene editing in human hematopoietic stem and progenitor cells. Nat. Med. 24, 1216-1224 (2018).

28. Wu, Y. et al. Highly efficient therapeutic gene editing of human hematopoietic stem cells. Nat. Med. 25, 776-783 (2019).

29. Biasco, L. et al. In vivo tracking of human hematopoiesis reveals patterns of clonal dynamics during early and steady-state reconstitution phases. Cell Stem Cell 19, 107-119 (2016)

30. Rheinwald, J. G. \& Green, H. Serial cultivation of strains of human epidermal keratinocytes: the formation of keratinizing colonies from single cells. Cell 6, 331-343 (1975).

31. Green, H., Kehinde, O. \& Thomas, J. Growth of cultured human epidermal cells into multiple epithelia suitable for grafting. Proc. Natl Acad. Sci. USA 76, 5665-5668 (1979).

32. Gallico, G. G. III, O’Connor, N. E., Compton, C. C., Kehinde, O. \& Green, H. Permanent coverage of large burn wounds with autologous cultured human epithelium. N. Engl. J. Med. 311, 448-451 (1984).

33. De Luca, M., Pellegrini, G. \& Green, H. Regeneration of squamous epithelia from stem cells of cultured grafts. Regen. Med. 1, 45-57 (2006).

34. Barrandon, Y. \& Green, H. Three clonal types of keratinocyte with different capacities for multiplication. Proc. Natl Acad. Sci. USA 84, 2302-2306 (1987).

35. Pellegrini, G. et al. The control of epidermal stem cells (holoclones) in the treatment of massive full-thickness burns with autologous keratinocytes cultured on fibrin. Transplantation 68, 868-879 (1999).

36. Ronfard, V., Rives, J. M., Neveux, Y., Carsin, H. \& Barrandon, Y. Long-term regeneration of human epidermis on third degree burns transplanted with autologous cultured epithelium grown on a fibrin matrix. Transplantation 70, 1588-1598 (2000).

37. Rama, P. et al. Limbal stem-cell therapy and long-term corneal regeneration. N. Engl. J. Med. 363, 147-155 (2010).

38. Hirsch, T. et al. Regeneration of the entire human epidermis using transgenic stem cells. Nature 551, 327-332 (2017).

39. Pellegrini, G. et al. Location and clonal analysis of stem cells and their differentiated progeny in the human ocular surface. J. Cell Biol. 145 769-782 (1999).

40. Schermer, A., Galvin, S. \& Sun, T. T. Differentiation-related expression of a major $64 \mathrm{~K}$ corneal keratin in vivo and in culture suggests limbal location of corneal epithelial stem cells. J. Cell Biol. 103, 49-62 (1986).

41. Cotsarelis, G., Cheng, S. Z., Dong, G., Sun, T. T. \& Lavker, R. M. Existence of slow-cycling limbal epithelial basal cells that can be preferentially stimulated to proliferate: implications on epithelial stem cells. Cell 57, 201-209 (1989)

42. Lehrer, M. S., Sun, T. T. \& Lavker, R. M. Strategies of epithelial repair: modulation of stem cell and transit amplifying cell proliferation. J. Cell Sci. 111, 2867-2875 (1998)

43. Majo, F., Rochat, A., Nicolas, M., Jaoudé, G. A. \& Barrandon, Y Oligopotent stem cells are distributed throughout the mammalian ocular surface. Nature 456, 250-254 (2008).

44. Pellegrini, G., Rama, P., Mavilio, F. \& De Luca, M. Epithelial stem cells in corneal regeneration and epidermal gene therapy. J. Pathol. 217, 217-228 (2009).

45. Kenyon, K. R. \& Tseng, S. C. Limbal autograft transplantation for ocular surface disorders. Ophthalmology 96, 709-723 (1989).

46. Lindberg, K., Brown, M. E., Chaves, H. V., Kenyon, K. R. \& Rheinwald, J. G. In vitro propagation of human ocular surface epithelial cells for transplantation. Invest. Ophthalmol. Vis. Sci. 34, 2672-2679 (1993).

47. Pellegrini, G. et al. Long-term restoration of damaged corneal surfaces with autologous cultivated corneal epithelium. Lancet 349, 990-993 (1997).

48. Rama, P. et al. Autologous fibrin-cultured limbal stem cells permanently restore the corneal surface of patients with total limbal stem cell deficiency. Transplantation 72, 1478-1485 (2001).

49. Pellegrini, G. et al. Biological parameters determining the clinical outcome of autologous cultures of limbal stem cells. Regen. Med. 8, 553-567 (2013).

50. Hsu, Y. C., Li, L. \& Fuchs, E. Transit-amplifying cells orchestrate stem cell activity and tissue regeneration. Cell 157, 935-949 (2014).

51. Yang, A. et al. p63, a p53 homolog at 3q27-29, encodes multiple products with transactivating, death-inducing, and dominant-negative activities. Mol. Cell 2, 305-316 (1998).

52. Yang, A. et al. p63 is essential for regenerative proliferation in limb, craniofacial and epithelial development. Nature 398, 714-718 (1999).

53. Mills, A. A. et al. p63 is a p53 homologue required for limb and epidermal morphogenesis. Nature 398, 708-713 (1999).

54. Senoo, M., Pinto, F., Crum, C. P. \& McKeon, F. p63 Is essential for the proliferative potential of stem cells in stratified epithelia. Cell $\mathbf{1 2 9}$, 523-536 (2007).

55. Pellegrini, G. et al. p63 identifies keratinocyte stem cells. Proc. Natl Acad. Sci. USA 98, 3156-3161 (2001).

56. Di Iorio, E. et al. Isoforms of DeltaNp63 and the migration of ocular limbal cells in human corneal regeneration. Proc. Natl Acad. Sci. USA 102, 9523-9528 (2005).

57. Di Iorio, E. et al. Q-FIHC: quantification of fluorescence immunohistochemistry to analyse p63 isoforms and cell cycle phases in human limbal stem cells. Microsc. Res. Tech. 69, 983-991 (2006).

58. Le, Q., Xu, J. \& Deng, S. X. The diagnosis of limbal stem cell deficiency. Ocul. Surf. 16, 58-69 (2018).

59. Dong, Y., Peng, H. \& Lavker, R. M. Emerging therapeutic strategies for limbal stem cell deficiency. J. Ophthalmol. 2018, 7894647 (2018).

60. Fine, J. D. et al. Inherited epidermolysis bullosa: updated recommendations on diagnosis and classification. J. Am. Acad. Dermatol. 70, 1103-1126 (2014)

61. Carulli, S., Contin, R., De Rosa, L., Pellegrini, G. \& De Luca, M. The long and winding road that leads to a cure for epidermolysis bullosa. Regen. Med. 8, 467-481 (2013).

62. Mavilio, F. et al. Correction of junctional epidermolysis bullosa by transplantation of genetically modified epidermal stem cells. Nat. Med. 12, 1397-1402 (2006).

63. Bauer, J. W. et al. Closure of a large chronic wound through transplantation of gene-corrected epidermal stem cells. J. Invest. Dermatol. 137 , 778-781 (2017).

64. Siprashvili, Z. et al. Safety and wound outcomes following genetically corrected autologous epidermal grafts in patients with recessive dystrophic epidermolysis bullosa. J. Am. Med. Assoc. 316, 1808-1817 (2016).

65. Clayton, E. et al. A single type of progenitor cell maintains normal epidermis. Nature 446, 185-189 (2007).

66. Mascré, G. et al. Distinct contribution of stem and progenitor cells to epidermal maintenance. Nature 489, 257-262 (2012).

67. Comai, G. \& Tajbakhsh, S. Molecular and cellular regulation of skeletal myogenesis. Curr. Top. Dev. Biol. 110, 1-73 (2014).

68. Miquerol, L. \& Kelly, R. G. Organogenesis of the vertebrate heart. Wiley Interdiscip. Rev. Dev. Biol. 2, 17-29 (2013).

69. Buckingham, M. Tissue differentiation: a personal account of research on myogenesis and cardiogenesis. Curr. Top. Dev. Biol. 116, 135-151 (2016).

70. Chang, N. C. \& Rudnicki, M. A. Satellite cells: the architects of skeletal muscle. Curr. Top. Dev. Biol. 107, 161-181 (2014).

71. Mercola, M., Ruiz-Lozano, P. \& Schneider, M. D. Cardiac muscle regeneration: lessons from development. Genes Dev. 25, 299-309 (2011).

72. Chong, J. J., Forte, E. \& Harvey, R. P. Developmental origins and lineage descendants of endogenous adult cardiac progenitor cells. Stem Cell Res. 13, 592-614 (2014) 
73. Porrello, E. R. et al. Transient regenerative potential of the neonatal mouse heart. Science 331, 1078-1080 (2011).

74. Chien, K. R. et al. Regenerating the field of cardiovascular cell therapy. Nat. Biotechnol. 37, 232-237 (2019).

75. Mauro, A. Satellite cell of skeletal muscle fibers. J. Biophys. Biochem. Cytol. 9, 493-495 (1961).

76. Buckingham, M. \& Rigby, P. W. Gene regulatory networks and transcriptional mechanisms that control myogenesis. Dev. Cell 28, 225-238 (2014).

77. Zammit, P. S. et al. Muscle satellite cells adopt divergent fates: a mechanism for self-renewal? J. Cell Biol. 166, 347-357 (2004).

78. Rocheteau, P., Gayraud-Morel, B., Siegl-Cachedenier, I., Blasco, M. A. \& Tajbakhsh, S. A subpopulation of adult skeletal muscle stem cells retains all template DNA strands after cell division. Cell 148, 112-125 (2012).

79. Guiraud, S. et al. The pathogenesis and therapy of muscular dystrophies. Annu. Rev. Genomics Hum. Genet. 16, 281-308 (2015).

80. Partridge, T. A., Morgan, J. E., Coulton, G. R., Hoffman, E. P. \& Kunkel, L. M. Conversion of mdx myofibres from dystrophin-negative to -positive by injection of normal myoblasts. Nature 337, 176-179 (1989).

81. Miller, R. G. et al. Myoblast implantation in Duchenne muscular dystrophy: the San Francisco study. Muscle Nerve 20, 469-478 (1997).

82. Gussoni, E. et al. Normal dystrophin transcripts detected in Duchenne muscular dystrophy patients after myoblast transplantation. Nature 356, 435-438 (1992).

83. Péault, B. et al. Stem and progenitor cells in skeletal muscle development, maintenance, and therapy. Mol. Ther. 15, 867-877 (2007).

84. Périé, S. et al. Autologous myoblast transplantation for oculopharyngeal muscular dystrophy: a phase I/IIa clinical study. Mol. Ther. 22, 219-225 (2014).

85. Boyer, O. et al. Autologous myoblasts for the treatment of fecal incontinence: results of a phase 2 randomized placebo-controlled study (MIAS). Ann. Surg. 267, 443-450 (2018).

86. Peters, K. M. et al. Autologous muscle derived cells for treatment of stress urinary incontinence in women. J. Urol. 192, 469-476 (2014).

87. Lin, C. S. \& Lue, T. F. Stem cell therapy for stress urinary incontinence: a critical review. Stem Cells Dev. 21, 834-843 (2012).

88. Mitchell, K. J. et al. Identification and characterization of a non-satellite cell muscle resident progenitor during postnatal development. Nat. Cell Biol. 12 257-266 (2010).

89. Joe, A. W. et al. Muscle injury activates resident fibro/adipogenic progenitors that facilitate myogenesis. Nat. Cell Biol. 12, 153-163 (2010).

90. Dellavalle, A. et al. Pericytes of human skeletal muscle are myogenic precursors distinct from satellite cells. Nat. Cell Biol. 9, 255-267 (2007).

91. Dellavalle, A. et al. Pericytes resident in postnatal skeletal muscle differentiate into muscle fibres and generate satellite cells. Nat. Commun. 2, 499 (2011).

92. Cossu, G. et al. Intra-arterial transplantation of HLA-matched donor mesoangioblasts in Duchenne muscular dystrophy. EMBO Mol. Med. 7, 1513-1528 (2015).

93. Clifford, D. M. et al. Stem cell treatment for acute myocardial infarction. Cochrane Database Syst. Rev. 2012, CD006536 (2012).

94. Orlic, D. et al. Bone marrow cells regenerate infarcted myocardium. Nature 410, 701-705 (2001)

95. Zhang, Y., Mignone, J. \& MacLellan, W. R. Cardiac Regeneration and Stem Cells. Physiol. Rev. 95, 1189-1204 (2015).

96. Harvey, R. P., Graham, R. M. \& Pu, W. T. Introduction to the special issue on heart regeneration and rejuvenation. Stem Cell Res. 13, 521-522 (2014).

97. Gerbin, K. A. \& Murry, C. E. The winding road to regenerating the human heart. Cardiovasc. Pathol. 24, 133-140 (2015).

98. Li, Y. et al. Genetic lineage tracing of non-myocyte population by dual recombinases. Circulation 138, 793-805 (2018).

99. Lee, J. H., Protze, S. I., Laksman, Z., Backx, P. H. \& Keller, G. M. Human pluripotent stem cell-derived atrial and ventricular cardiomyocytes develop from distinct mesoderm populations. Cell Stem Cell 21, 179-194.e174 (2017)

100. Giacomelli, E., Mummery, C. L. \& Bellin, M. Human heart disease: lessons from human pluripotent stem cell-derived cardiomyocytes. Cell. Mol. Life Sci. 74, 3711-3739 (2017).

101. Yang, X., Pabon, L. \& Murry, C. E. Engineering adolescence: maturation of human pluripotent stem cell-derived cardiomyocytes. Circ. Res. 114, 511-523 (2014).

102. Liu, Y. W. et al. Human embryonic stem cell-derived cardiomyocytes restore function in infarcted hearts of non-human primates. Nat. Biotechnol. 36, 597-605 (2018).

103. Veerman, C. C. et al. Immaturity of human stem-cell-derived cardiomyocytes in culture: fatal flaw or soluble problem? Stem Cells Dev. 24, 1035-1052 (2015).

104. Coulombe, K. L., Bajpai, V. K., Andreadis, S. T. \& Murry, C. E. Heart regeneration with engineered myocardial tissue. Annu. Rev. Biomed. Eng. 16, 1-28 (2014).
105. Fu, J. D. \& Srivastava, D. Direct reprogramming of fibroblasts into cardiomyocytes for cardiac regenerative medicine. Circ. J. 79, 245-254 (2015).

106. Farouz, Y., Chen, Y., Terzic, A. \& Menasché, P. Concise review: growing hearts in the right place: on the design of biomimetic materials for cardiac stem cell differentiation. Stem Cells 33, 1021-1035 (2015).

107. D'Uva, G. et al. ERBB2 triggers mammalian heart regeneration by promoting cardiomyocyte dedifferentiation and proliferation. Nat. Cell Biol. 17, 627-638 (2015).

108. Mikkers, H. M., Freund, C., Mummery, C. L. \& Hoeben, R. C. Cell replacement therapies: is it time to reprogram? Hum. Gene Ther. 25, 866-874 (2014).

109. Bianco, P. et al. The meaning, the sense and the significance: translating the science of mesenchymal stem cells into medicine. Nat. Med. 19, 35-42 (2013).

110. Bianco, P., Robey, P. G. \& Simmons, P. J. Mesenchymal stem cells: revisiting history, concepts, and assays. Cell Stem Cell 2, 313-319 (2008).

111. Owen, M. \& Friedenstein, A. J. Stromal stem cells: marrow-derived osteogenic precursors. Ciba Found. Symp. 136, 42-60 (1988).

112. Bianco, P. \& Robey, P.G. in Handbook of Adult and Fetal Stem Cells (eds Lanza, R. et al.) 415-424 (San Diego, Academic Press, 2004).

113. Caplan, A. I. Mesenchymal stem cells. J. Orthop. Res. 9, 641-650 (1991).

114. Bianco, P. \& Robey, P. G. Skeletal stem cells. Development 142 , 1023-1027 (2015)

115. Galipeau, J. \& Sensébé, L. Mesenchymal stromal cells: clinical challenges and therapeutic opportunities. Cell Stem Cell 22, 824-833 (2018).

116. Kuriyan, A. E. et al. Vision loss after intravitreal injection of autologous "stem cells" for AMD. N. Engl. J. Med. 376, 1047-1053 (2017).

117. Caplan, A. I. \& Correa, D. The MSC: an injury drugstore. Cell Stem Cell 9, 11-15 (2011).

118. Phinney, D. G. \& Prockop, D. J. Concise review: mesenchymal stem/ multipotent stromal cells: the state of transdifferentiation and modes of tissue repair-current views. Stem Cells 25, 2896-2902 (2007).

119. Bianco, P. et al. Regulation of stem cell therapies under attack in Europe: for whom the bell tolls. EMBO J. 32, 1489-1495 (2013).

120. Bartunek, J. et al. Cardiopoietic cell therapy for advanced ischaemic heart failure: results at 39 weeks of the prospective, randomized, double blind, sham-controlled CHART-1 clinical trial. Eur. Heart J. 38, 648-660 (2017).

121. Herreros, M. D., Garcia-Arranz, M., Guadalajara, H., De-La-Quintana, P. \& Garcia-Olmo, D. Autologous expanded adipose-derived stem cells for the treatment of complex cryptoglandular perianal fistulas: a phase III randomized clinical trial (FATT 1: fistula Advanced Therapy Trial 1) and long-term evaluation. Dis. Colon Rectum 55, 762-772 (2012).

122. Sipp, D., Robey, P. G. \& Turner, L. Clear up this stem-cell mess. Nature 561, 455-457 (2018).

123. Dominici, M. et al. Minimal criteria for defining multipotent mesenchymal stromal cells. The International Society for Cellular Therapy position statement. Cytotherapy 8, 315-317 (2006).

124. Sacchetti, B. et al. No identical "mesenchymal stem cells" at different times and sites: human committed progenitors of distinct origin and differentiation potential are incorporated as adventitial cells in microvessels. Stem Cell Reports 6, 897-913 (2016).

125. Shi, S. \& Gronthos, S. Perivascular niche of postnatal mesenchymal stem cells in human bone marrow and dental pulp. J. Bone Miner. Res. 18, 696-704 (2003).

126. Sacchetti, B. et al. Self-renewing osteoprogenitors in bone marrow sinusoids can organize a hematopoietic microenvironment. Cell 131, 324-336 (2007).

127. Zhou, B. O., Yue, R., Murphy, M. M., Peyer, J. G. \& Morrison, S. J. Leptin-receptor-expressing mesenchymal stromal cells represent the main source of bone formed by adult bone marrow. Cell Stem Cell 15, 154-168 (2014).

128. Guimaraes-Camboa, N. et al. Pericytes of multiple organs do not behave as mesenchymal stem cells in vivo. Cell Stem Cell 20, 345-359.e345 (2017).

129. Quarto, R. et al. Repair of large bone defects with the use of autologous bone marrow stromal cells. N. Engl. J. Med. 344, 385-386 (2001).

130. Lee, J. et al. Successful reconstruction of $15-\mathrm{cm}$ segmental defects by bone marrow stem cells and resected autogenous bone graft in central hemangioma. J. Oral Maxillofac. Surg. 68, 188-194 (2010).

131. Yamada, Y., Ueda, M., Hibi, H. \& Baba, S. A novel approach to periodontal tissue regeneration with mesenchymal stem cells and platelet-rich plasma using tissue engineering technology: a clinical case report. Int. J. Periodontics Restorative Dent. 26, 363-369 (2006).

132. Robey, P. G. Cell sources for bone regeneration: the good, the bad, and the ugly (but promising). Tissue Eng. Part B Rev. 17, 423-430 (2011).

133. Nakashima, M. et al. Pulp regeneration by transplantation of dental pulp stem cells in pulpitis: a pilot clinical study. Stem Cell Res. Ther. 8, 61 (2017).

134. Bachoud-Lévi, A. C. From open to large-scale randomized cell transplantation trials in Huntington's disease: lessons from the multicentric intracerebral grafting in Huntington's disease trial (MIG-HD) and previous pilot studies. Prog. Brain Res. 230, 227-261 (2017). 
135. Barker, R. A., Drouin-Ouellet, J. \& Parmar, M. Cell-based therapies for Parkinson disease-past insights and future potential. Nat. Rev. Neurol. 11, 492-503 (2015).

136. Barker, R. A., Parmar, M., Studer, L. \& Takahashi, J. Human trials of stem cell-derived dopamine neurons for Parkinson's disease: dawn of a new era. Cell Stem Cell 21, 569-573 (2017).

137. Kalladka, D. et al. Human neural stem cells in patients with chronic ischaemic stroke (PISCES): a phase 1, first-in-man study. Lancet 388, 787-796 (2016).

138. Lindvall, O. \& Kokaia, Z. Stem cell research in stroke: how far from the clinic? Stroke 42, 2369-2375 (2011).

139. Shirai, H. et al. Transplantation of human embryonic stem cell-derived retinal tissue in two primate models of retinal degeneration. Proc. Natl Acad. Sci. USA 113, E81-E90 (2016)

140. Whiting, P., Kerby, J., Coffey, P., da Cruz, L. \& McKernan, R. Progressing a human embryonic stem-cell-based regenerative medicine therapy towards the clinic. Phil. Trans. R. Soc. Lond. B 370, 20140375 (2015).

141. Priest, C. A., Manley, N. C., Denham, J., Wirth, E. D. III \& Lebkowski, J. S. Preclinical safety of human embryonic stem cell-derived oligodendrocyte progenitors supporting clinical trials in spinal cord injury. Regen. Med. 10, 939-958 (2015).

142. da Cruz, L. et al. Phase 1 clinical study of an embryonic stem cell-derived retinal pigment epithelium patch in age-related macular degeneration. Nat. Biotechnol. 36, 328-337 (2018)

143. Mandai, M., Kurimoto, Y. \& Takahashi, M. Autologous induced stem-cellderived retinal cells for macular degeneration. N. Engl. J. Med. 377, 792-793 (2017).

144. Damier, P., Hirsch, E. C., Agid, Y. \& Graybiel, A. M. The substantia nigra of the human brain. II. Patterns of loss of dopamine-containing neurons in Parkinson's disease. Brain 122, 1437-1448 (1999).

145. Jenner, P. Dopamine agonists, receptor selectivity and dyskinesia induction in Parkinson's disease. Curr. Opin. Neurol. 16 Suppl 1, S3-S7 (2003).

146. Huot, P., Johnston, T. H., Koprich, J. B., Fox, S. H. \& Brotchie, J. M. The pharmacology of L-DOPA-induced dyskinesia in Parkinson's disease. Pharmacol. Rev. 65, 171-222 (2013).

147. Lindvall, O. et al. Human fetal dopamine neurons grafted into the striatum in two patients with severe Parkinson's disease. A detailed account of methodology and a 6-month follow-up. Arch. Neurol. 46, 615-631 (1989).

148. Lindvall, O. et al. Grafts of fetal dopamine neurons survive and improve motor function in Parkinson's disease. Science 247, 574-577 (1990).

149. Kefalopoulou, Z. et al. Long-term clinical outcome of fetal cell transplantation for Parkinson disease: two case reports. JAMA Neurol. 71, 83-87 (2014)

150. Piccini, P. et al. Dopamine release from nigral transplants visualized in vivo in a Parkinson's patient. Nat. Neurosci. 2, 1137-1140 (1999).

151. Kordower, J. H. et al. Neuropathological evidence of graft survival and striatal reinnervation after the transplantation of fetal mesencephalic tissue in a patient with Parkinson's disease. N. Engl. J. Med. 332, 1118-1124 (1995)

152. Li, W. et al. Extensive graft-derived dopaminergic innervation is maintained 24 years after transplantation in the degenerating parkinsonian brain. Proc. Natl Acad. Sci. USA 113, 6544-6549 (2016).

153. Li, J. Y. et al. Characterization of Lewy body pathology in 12- and 16-year-old intrastriatal mesencephalic grafts surviving in a patient with Parkinson's disease. Mov. Disord. 25, 1091-1096 (2010).

154. Kordower, J. H., Chu, Y., Hauser, R. A., Freeman, T. B. \& Olanow, C. W. Lewy body-like pathology in long-term embryonic nigral transplants in Parkinson's disease. Nat. Med. 14, 504-506 (2008).
155. Ribeiro, D. et al. Efficient expansion and dopaminergic differentiation of human fetal ventral midbrain neural stem cells by midbrain morphogens. Neurobiol. Dis. 49, 118-127 (2013).

156. Thomson, J. A. et al. Embryonic stem cell lines derived from human blastocysts. Science 282, 1145-1147 (1998)

157. Takahashi, $\mathrm{K}$. et al. Induction of pluripotent stem cells from adult human fibroblasts by defined factors. Cell 131, 861-872 (2007).

158. Kriks, S. et al. Dopamine neurons derived from human ES cells efficiently engraft in animal models of Parkinson's disease. Nature 480, 547-551 (2011).

159. Kirkeby, A. et al. Generation of regionally specified neural progenitors and functional neurons from human embryonic stem cells under defined conditions. Cell Rep. 1, 703-714 (2012)

160. Grealish, S. et al. Human ESC-derived dopamine neurons show similar preclinical efficacy and potency to fetal neurons when grafted in a rat model of Parkinson's disease. Cell Stem Cell 15, 653-665 (2014).

161. Kikuchi, T. et al. Human iPS cell-derived dopaminergic neurons function in a primate Parkinson's disease model. Nature 548, 592-596 (2017).

162. Kirkeby, A., Parmar, M. \& Barker, R. A. Strategies for bringing stem cell-derived dopamine neurons to the clinic: a European approach (STEM-PD). Prog. Brain Res. 230, 165-190 (2017).

163. Studer, L. Strategies for bringing stem cell-derived dopamine neurons to the clinic-The NYSTEM trial. Prog. Brain Res. 230, 191-212 (2017).

164. Takahashi, J. Strategies for bringing stem cell-derived dopamine neurons to the clinic: the Kyoto trial. Prog. Brain Res. 230, 213-226 (2017).

165. Abbott, A. Fetal-cell revival for Parkinson's. Nature $\mathbf{5 1 0}$ 195-196 (2014).

\section{Acknowledgements}

The authors would to thank the following parties, from whose work elements of our figures were modified; F. Aiuti (Fig. 2a), A. De Luca (Fig. 3a), and J. Drouin-Ouellet (Fig. 4). This work was partially supported by Regione Emilia-Romagna, Asse 1 POR-FESR 2007-13 to M.D.L. and G.P.; Italian Telethon Foundation to A.A.; Division of Intramural Research, National Institute of Dental Research, a part of the Intramural Research Program, the National Institutes of Health, Department of Health and Humman Services (ZIA DE000380 to P.G.R.), the Wellcome Trust (ME070401A1), the MRC (MR/P016006/1) the GOSH-SPARKS charity (V4618) to G.C.

\section{Competing interests}

M.D.L. and G.P. are members of the Board of Directors of Holostem Terapie Avanzate Srl and consultant at J-TEC Ltd, Japan Tissue Engineering. A.A. is the principal investigator of clinical trials of HSC-GT for ADA-SCID, MLD and Wiskott-Aldrich, sponsored by Orchard Therapeutics. Orchard Therapeutic is the marketing authorization holder of Strimvelis in the European Union. M.P. is the owner of Parmar Cells AB and co-inventor of the US patent application 15/093,927 owned by Biolamina AB and EP17181588 owned by Miltenyi Biotec. M.P. is a New York Stem Cell Foundation Robertson Investigator.

\section{Additional information}

Reprints and permissions information is available at www.nature.com/reprints. Correspondence should be addressed to M.D.

Publisher's note: Springer Nature remains neutral with regard to jurisdictional claims in published maps and institutional affiliations.

(C) Springer Nature Limited 2019 